\title{
Article \\ Pigment and Fatty Acid Production under Different Light Qualities in the Diatom Phaeodactylum tricornutum
}

\author{
Bernardo Duarte ${ }^{1,2, *(\mathbb{D})}$, Eduardo Feijão ${ }^{1}$, Johannes W. Goessling ${ }^{3}$, Isabel Caçador ${ }^{1,2}$ and Ana Rita Matos ${ }^{2,4} \mathbb{D}^{(D)}$ \\ 1 MARE-Marine and Environmental Sciences Centre, Faculdade de Ciências da Universidade de Lisboa, \\ Campo Grande, 1749-016 Lisboa, Portugal; emfeijao@fc.ul.pt (E.F.); micacador@fc.ul.pt (I.C.) \\ 2 Departamento de Biologia Vegetal, Faculdade de Ciências da Universidade de Lisboa, Campo Grande, \\ 1749-016 Lisboa, Portugal; armatos@fc.ul.pt \\ 3 International Iberian Nanotechnology Laboratory, 4715-330 Braga, Portugal; johannes.goessling@inl.int \\ 4 Plant Functional Genomics Group, BioISI-Biosystems and Integrative Sciences Institute, \\ Faculdade de Ciências da Universidade de Lisboa, Campo Grande, 1749-016 Lisboa, Portugal \\ * Correspondence: baduarte@fc.ul.pt
}

check for

updates

Citation: Duarte, B.; Feijão, E.; Goessling, J.W.; Caçador, I.; Matos, A.R. Pigment and Fatty Acid Production under Different Light Qualities in the Diatom Phaeodactylum tricornutum. Appl. Sci. 2021, 11, 2550. https://doi.org/10.3390/ app11062550

Academic Editor: Guillaume Pierre

Received: 24 February 2021

Accepted: 8 March 2021

Published: 12 March 2021

Publisher's Note: MDPI stays neutral with regard to jurisdictional claims in published maps and institutional affiliations.

Copyright: (c) 2021 by the authors. Licensee MDPI, Basel, Switzerland. This article is an open access article distributed under the terms and conditions of the Creative Commons Attribution (CC BY) license (https:/ / creativecommons.org/licenses/by/ $4.0 /)$.
Featured Application: light emitting diodes (LED) illumination with different wavelengths can modulate diatom ca-rotenoid and fatty acid production.

\begin{abstract}
Diatoms are microscopic biorefineries producing value-added molecules, including unique pigments, triglycerides (TAGs) and long-chain polyunsaturated fatty acids (LC-PUFAs), with potential implications in aquaculture feeding and the food or biofuel industries. These molecules are utilized in vivo for energy harvesting from sunlight to drive photosynthesis and as photosynthetic storage products, respectively. In the present paper, we evaluate the effect of narrow-band spectral illumination on carotenoid, LC-PUFAs and TAG contents in the model diatom Phaeodactylum tricornutum. Shorter wavelengths in the blue spectral range resulted in higher production of total fatty acids, namely saturated TAGs. Longer wavelengths in the red spectral range increased the cell's content in Hexadecatrienoic acid (HTA) and Eicosapentaenoic acid (EPA). Red wavelengths induced higher production of photoprotective carotenoids, namely fucoxanthin. In combination, the results demonstrate how diatom value-added molecule production can be modulated by spectral light control during the growth. How diatoms could use such mechanisms to regulate efficient light absorption and cell buoyancy in the open ocean is discussed.
\end{abstract}

Keywords: Phaedactylum tricornutum; photochemistry; fucoxanthin; single wavelength LEDs

\section{Introduction}

Diatoms (Bacillariophyta) are among the most abundant phytoplankton species on Earth [1]. They play vital roles as primary producers in aquatic food webs, being responsible for half of the organic materials in the ocean and up to $20 \%$ of the Earth's oxygen produced by photosynthesis [1]. Their high productivity has attracted scientific study related to their biotechnological potential, e.g., as biorefineries [2]. Diatoms have thereby mainly been exploited by the nutraceutical, fuel and aquaculture sectors, emerging as novel bioresources for the production of bioenergy, food and aquaculture feed, and as supporter of wastewater bioremediation [3]. Besides the most recent approaches to improve microalgae value-added yield production, using genetic engineering and molecular biology approaches [4], the manipulation of culture conditions (e.g., the light availability) has also been investigated [5]. The unique products of diatoms originate from their photosynthetic metabolism. Fucoxanthin (Fx) is a primary carotenoid with expanded light absorption in the cyan and green spectral range of light. It has drawn attention due to its antioxidative properties, as potential antiobesity, and potential anticancer compound as well as some suggested effects to mitigate Alzheimer's disease [6-8]. Today, the main commercially 
available source of Fx is brown seaweeds (Stramenopiles), a phylogenetic group to which the diatoms also belong [9]. Diatoms store photosynthetic energy foremost in form of fatty acids, with high proportions of polyunsaturated fatty acids (PUFAs), namely $\omega 3$ fatty acids such as eicosapentaenoic acid (20:5, EPA) (Dunstan et al., 1993). Additionally, diatoms show high amounts of storage lipids (triacylglycerols, TAG) [10], with high nutritional value [11] and are useful for aquaculture feeding and potentially biofuel production [12].

Diatoms require light for their growth, as their metabolism bases on photosynthesis as primary energy source [13]. Some common cultivation systems involve light emitting diodes (LEDs) to support algal growth in cell cultures at the maximum light absorption of the main photosynthetic pigments, in the blue and red spectral range of light at ca. $\lambda \approx 450 \mathrm{~nm}$ and $\lambda \approx 650 \mathrm{~nm}$, respectively [5]. The narrow-band wavelengths of LEDs can also be applied to test physiological implications of particular spectral parts of light and metabolite production under more environmental-like conditions, where light intensity as well as light spectral composition are affected by the wavelengths dependent light attenuation characteristics of water [14]. Individuals near the surface might thereby receive significantly higher amounts of light, compared to cells located at subsurface layers in the water column. In addition, light wavelengths of higher energy in the blue spectral range can penetrate deeper in the absence of dissolved organic matter and microscale particles [15]. In consequence, individuals of the same species can be projected to significant differences of available light during their lifetime. The different wavelengths to which diatoms are subjected in their natural environment and at different life stages are key factors shaping the metabolic activity of the cells [16]. The presence of blue and red light photoreceptors, i.e., cryptochromes and aureochromes, and phytochromes, respectively, allows diatoms to sense their position in the water column and to perform morphological and physiological alterations to adapt to changes in environmental conditions $[17,18]$.

In the present work, we studied the effects of narrow-band illumination with blue and red light LEDs compared to red-green-blue (RGB) LEDs upon photo-pigment, lipid and fatty acid production in the diatom Phaeodactylum tricornutum. Different pulse amplitude modulated (PAM) chlorophyll fluorescence techniques were used to determine the energy flux and dissipation along the photosynthetic transport chain under these illumination conditions. Phaeodactylum tricornutum is a well characterized model diatom, which can be cultivated in several culture media [2]. It is known for a variety of marketable products and today commercially viable for large-scale cultivation in some cases [2]. The data presented here suggest that spectral illumination conditions can modulate pigment concentrations and the composition of fatty acids, paving the way for optimized production of these high-value products in P. tricornutum. We speculate that some can regulate their position in the water column by a fine-tuned interplay of light absorption by photo-pigments and the composition and quantity of photosynthetic storage lipids to control the cell buoyancy.

\section{Materials and Methods}

\subsection{Culture Conditions}

Phaeodactylum tricornutum Bohlin (Bacillariophyceae; strain IO 108-01, Instituto Português do Mar e da Atmosfera (IPMA)) axenic cell cultures were placed to grow in f/2 medium [19], under constant aeration in a phytoclimatic chamber (FytoScope FS 130RGBIR, Photon Systems Instruments, Czech Republic), at $18{ }^{\circ} \mathrm{C}$, programmed with a $14 / 10 \mathrm{~h}$ day/night photoperiod using a sinusoidal function provided by the manufacturer to mimic sunrise and sunset, and light intensity at noon, set to replicate a natural light environment, with a maximum light intensity of $80 \mu \mathrm{mol}$ photons $\mathrm{m}^{-2} \mathrm{~s}^{-1}$ at solar noon. [20]. Cultures were daily inspected visually under the microscope. Culture trials under the different light regimes were conducted according to the Organization for Economic Cooperation and Development (OECD) recommendations for algae assays [21], with minor adaptations, and the suggested initial cell density for microalgae cells with comparable dimensions to $P$. tricornutum (initial cell density $=2.7 \times 10^{5}$ cells $\mathrm{mL}^{-1}$ ). According to OECD guidelines, carbon dioxide concentrations were maintained through constant aeration of 
the cultures with ambient air. All manipulations were executed within a laminar flow hood chamber, ensuring standard aseptic conditions.

Light conditions were adjusted using the LED panel of the FytoScope FS 130-RGBIR. Full light treatment (denoted as RGB LED hereafter) was provided using a combination of RGB LEDs in the molar proportion 1:1:1 (Red $\lambda=627 \mathrm{~nm} /$ Green $\lambda=530 \mathrm{~nm} /$ Blue $\lambda=470 \mathrm{~nm}$ ). Red light treatment (denoted as Red LED hereafter), was preformed using only the Red LEDs $(\lambda=627 \mathrm{~nm})$. Blue light treatment (denoted as Blue LED hereafter), was provided using only the Blue LEDs $(\lambda=470 \mathrm{~nm})$. All light intensities were adjusted in all light conditions to achieve a maximum photosynthetically active radiation (PAR) of $80 \mu \mathrm{mol}$ photons $\mathrm{m}^{-2} \mathrm{~s}^{-1}$ at solar noon, at the culture flasks level. After inoculation cultures were immediately exposed to the targeted light treatment, and the experiment lasted for $96 \mathrm{~h}$.

\subsection{Diatom Cell Density Measurements and Pellet Collection}

Phaeodactylum tricornutum cells ( $1 \mathrm{~mL}$ volume sample) were counted using a Neubauer improved counting chamber, coupled with an Olympus BX50 (Tokyo, Japan) inverted microscope, at 400-x magnification. At the end of the exposure trials, cells were harvested for biochemical analysis by centrifugation at $4000 \times \mathrm{g}$ for $15 \mathrm{~min}$ at $4{ }^{\circ} \mathrm{C}$ and the pellets were frozen in liquid nitrogen and stored at $-80^{\circ} \mathrm{C}$. Five biological replicates for all tested conditions were considered for total fatty acid analysis and pigment analysis and three replicates were considered for triacylglyceride (TAG) quantification.

\subsection{Chlorophyll a Pulse Amplitude Modulated Fluorometry}

At the end of the experimental period, and before cell harvesting, $1 \mathrm{~mL}$ of each replicate culture was used for bio-optical assessment, using chlorophyll-a pulse amplitude modulated (PAM) fluorometry (FluorPen FP100, Photo System Instruments, Brno, Czech Republic). Cell culture subsamples for bio-optical assessment were acclimated for $15 \mathrm{~min}$ in the dark and chlorophyll transient light curves were generated using the preprogrammed OJIP (fluorescence rise through four phases called O, J, I and P) protocol [22]. Rapid light curves (RLC) were generated using the preprogrammed LC1. The parameters determined and calculated by the software from this analysis are shown in Table $1[23,24]$.

Table 1. Summary of fluorometric analysis parameters and their description.

\begin{tabular}{|c|c|}
\hline Variable & Description \\
\hline$\Phi$ PSII & $\begin{array}{l}\text { Photosystem II (PSII) maximum quantum yield }\left(\mathrm{F}_{\mathrm{v}} / \mathrm{F}_{\mathrm{m}} \text {, where } \mathrm{F}_{\mathrm{v}} \text { is the variable fluorescence and } \mathrm{F}_{\mathrm{m}} \text { is the }\right. \\
\text { maximum fluorescence). }\end{array}$ \\
\hline$\alpha$ & $\begin{array}{l}\text { Photosynthetic efficiency, corresponding to the initial slope of the relative electron transport rate (rETR) versus } \\
\text { photosynthetic photon flux density (PPFD) curve. }\end{array}$ \\
\hline$Q_{\text {phar }} \alpha$ & $\begin{array}{l}\text { Photosynthetic efficiency, corresponding to the initial slope of the relative electron transport rate (rETR) versus } \\
\text { pigment weighted light absorption. }\end{array}$ \\
\hline rETR & $\begin{array}{l}\text { Relative electron transport rate, obtained from applying the equation: } \Phi \text { PSII } \times \text { PPFD } \times 0.5 \text { (factor for correcting for } \\
\text { the energy generated only at the PSII side, assuming each photosystem absorbs } 50 \% \text { of the incoming energy). }\end{array}$ \\
\hline ETR $_{\max }$ & Maximum ETR having as basis the PPFD. \\
\hline $\begin{array}{l}Q_{\text {phar }} \\
\text { ETR }_{\max }\end{array}$ & Maximum ETR calculated using the pigment weighted light absorption. \\
\hline AOECS & Active oxygen evolving complexes at the PSII donor side. \\
\hline $\mathrm{ABS} / \mathrm{CS}$ & Absorbed energy flux per cross-section. \\
\hline $\mathrm{TR} / \mathrm{CS}$ & Trapped energy flux per cross-section. \\
\hline $\mathrm{ET} / \mathrm{CS}$ & Electron transport energy flux per cross-section. \\
\hline $\mathrm{DI} / \mathrm{CS}$ & Dissipated energy flux per cross-section. \\
\hline $\mathrm{RC} / \mathrm{CS}$ & Number of available reaction centers per cross-section. \\
\hline
\end{tabular}




\subsection{Pigment Profiles}

Pigments were extracted from sample pellets with $100 \%$ cold acetone and maintained in a cold ultra-sound bath for $2 \mathrm{~min}$, to ensure complete disaggregation of the cell material. Extraction proceeded in the dark at $-20{ }^{\circ} \mathrm{C}$ for $24 \mathrm{~h}$, to prevent pigment degradation $[20,25,26]$. Following centrifugation $\left(4000 \times g\right.$ for $15 \mathrm{~min}$ at $\left.4{ }^{\circ} \mathrm{C}\right)$, supernatants were analyzed using a dual beam spectrophotometer. Absorbance spectrums from $350 \mathrm{~nm}$ to $750 \mathrm{~nm}$ (0.5 nm steps) were then introduced in the Gauss-peak spectra (GPS) fitting library, using SigmaPlot software. Pigment analysis was employed using the a gaussian peak deconvolution algorithm [27], enabling the detection of Chlorophyll a and c, Pheophytin a, $\beta$-carotene, Fx, Diadinoxanthin (DD), and Diatoxanthin (DT).

\subsection{Absorption Spectra}

To compare whether differences in light color responses were due to total light absorbed or due to light quality effects, a pigment weighted light absorption ( $Q_{\text {Phar }}$ ) was calculated [28] with modification [29]. $Q_{\text {Phar }}(\lambda)$ correspond to the amount and proportion of light absorbed by the cells at different wavelengths. The specific in vitro absorption coefficients of the P. tricornutum cultures $(P t)$ were reconstructed according to:

$$
a_{P t}(\lambda)=\sum_{i}^{n} a_{i}(\lambda) \times C_{i}
$$

where $a_{i}(\lambda)$ is the concentration specific absorption coefficient obtained from the literature for each pigment at each incident wavelength [30] and $C_{i}$ is the pigment concentration of the culture. For extraction of the correct absorption coefficient the predominant wavelengths of each of the LED light quality was used. The pigment weighted light absorption $Q_{\text {phar }}$ is obtained from:

$$
Q_{\text {phar }}=Q(\lambda)-\left[Q(\lambda) \times e^{-a_{P t}(\lambda)}\right]
$$

where $Q(\lambda)$ is the incident PAR in $\mu \mathrm{mol} \mathrm{m}{ }^{-2} \mathrm{~s}^{-1}$ [28]. The pigments used for spectral absorption reconstruction were chlorophyll a, chlorophyll c, pheophythin a, $\beta$-carotene, Fx, DD and DT.

\subsection{Total Fatty Acids and TAG Profiles}

Cell pellets for total fatty acid analysis were submitted to direct transesterification with freshly prepared methanol sulfuric acid $(97.5: 2.5, v / v)$ at $70{ }^{\circ} \mathrm{C}$ for $60 \mathrm{~min}$ [31]. Subsequently, fatty acids methyl esters (FAMEs) were recovered using petroleum ether and the solvent evaporated under a constant $\mathrm{N}_{2}$ flow in a dry bath at $30{ }^{\circ} \mathrm{C}$ [20,32]. FAMEs were resuspended in hexane and $1 \mu \mathrm{L}$ was injected in a gas chromatograph (Varian 430-GC gas chromatograph, Middelburg, The Netherlands), equipped with a hydrogen flame ionization detector set at $300{ }^{\circ} \mathrm{C}$. The temperature of the injector was set to $270{ }^{\circ} \mathrm{C}$, with a split ratio of 50. The fused-silica capillary column $(50 \mathrm{~m} \times 0.25 \mathrm{~mm}$; WCOT Fused Silica, CP-Sil 88 for FAME; Varian, Middelburg, The Netherlands) was maintained at a constant $\mathrm{N}_{2}$ flow of $2.0 \mathrm{~mL} \mathrm{~min}-1$ and the oven set at $190^{\circ} \mathrm{C}$. Fatty acids identification was achieved by comparison of retention times with standards (Sigma-Aldrich, St. Louis, MO, USA), and chromatograms analyzed by the peak surface method, using the Galaxy software (Varian, Inc., Palo Alto, CA, USA). The internal standard used was pentadecanoic acid (15:0) to identify losses during preparation.

Two indexes are commonly used to infer and predict the potential health benefits associated with the ingestion of a certain food: indexes of atherogenicity (IA) and thrombogenicity (IT) [33]:

$$
I A=\frac{4 \times C 14: 0+C 16: 0}{\sum M U F A+\sum P U F A-n 6+\sum P U F A-n 3}
$$




$$
I T=\frac{C 14: 0+C 16: 0}{0.5 \times M U F A+0.5 \times P U F A-n 6+3 \times P U F A-n 3+\frac{P U F A-n 3}{P U F A-n 6}}
$$

where MUFA and PUFA correspond to relative concentrations of the monounsaturated fatty acid (MUFA) and PUFA. The IA is related to the plaque formation and to the decrease in the levels of esterified fatty acid, cholesterol, and phospholipids, thereby preventing the appearance of micro- and macro-coronary diseases [33]. The IT is related to the tendency to form clots in the blood vessels [33].

For neutral lipids' separation pellets were boiled in water for $5 \mathrm{~min}$ to inactivate lipolytic enzymes. The extraction of lipophilic compounds was performed using a mixture of chloroform/methanol/water (1:1:1, v/v/v), as previously described [34]. Neutral lipid separation was achieved by thin layer chromatography (TLC) on silica plates (G-60, Merck, VWR) using as solvent a mixture of petroleum ether/ethyl ether/acetic acid $(70 / 30 / 0.4$, $v / v / v$ ) [35]. Lipids bands were visualized with $0.01 \%$ primuline in $80 \%$ acetone $(v / v)$ under UV light, and the lipid band correspondent to TAG scraped off and transesterified as above-mentioned for total fatty acids, using the scrapped portion as sample [36].

\subsection{Statistical Analysis}

As normality and homogeneity of variances of our data were not given, pairwise comparisons between different sample groups were performed through nonparametric Kruskal-Wallis tests. These were computed with Statistica software (StataSoft, version 12.5.192.7). Statistical significance was considered at the $p<0.05$. A multivariate approach was employed to test for variations in the complete photochemical, fatty acid and TAG profiles $[32,37,38]$. Canonical analysis of principle (CAP) coordinates, using Euclidean distances, were preformed to plot the dissimilarities in a canonical space regarding fatty acids and photochemical studied variables while preforming a cross-validation step and determining the allocation efficiency into the different treatment groups. This multivariate methodology is unaffected by heterogeneous data and frequently used to compare different sample assemblies using the inherent features of each assembly (metabolic traits) $[25,32,37,39]$. Multivariate statistical analyses were performed using Primer 6 software (version 6.1.13, Plymouth, UK) [40].

\section{Results}

\subsection{Diatom Cell Growth}

It was found that RGB and Blue LED treatments resulted in similar cell densities during the growth (Figure 1). However, Red LED treatment caused faster growth rates during the first $48 \mathrm{~h}(p<0.05)$, after which the growth rates converged with other treatments.

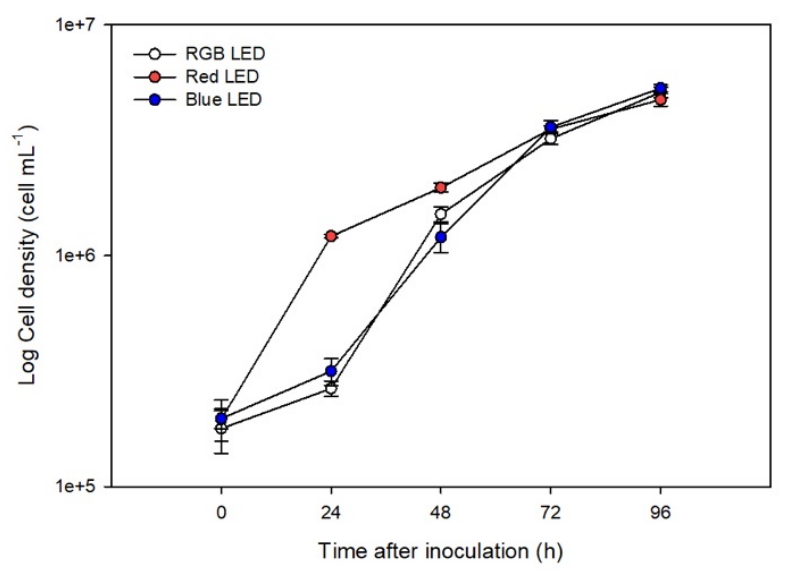

Figure 1. Growth curve of the P. tricornutum cultures $(N=5)$ subjected to the three light treatments during the $96 \mathrm{~h}$ exposure (average \pm standard error). 


\subsection{Photochemistry at Photosystem II}

Rapid light curve measurements (Figure 2a-c) showed that Red LED treatment resulted in reduced relative electron transport rate (rETR) (Figure 2a) when exposed to irradiances above $100 \mu \mathrm{mol}$ photons $\mathrm{m}^{-2} \mathrm{~s}^{-1}$, compared to the cultures subjected to the RGB and Blue LED treatments. This resulted in a lower photosynthetic efficiency (Figure $2 b$ ) and maximum electron transport rate (Figure 2c) under Red LED treatment. When these parameters are normalized with the pigment weighted light absorption $\left(Q_{\text {phar }}\right)$, cultures grown under Red LED treatment presented significantly higher $Q_{\text {phar }}$ photosynthetic efficiency (Figure 2d). On the other hand, the $Q_{\text {phar }}$ maximum ETR of the cells grown under Red LED treatment showed higher values of this parameters as compared to cells exposed to RGB LED treatment (Figure 2e). The cultures grown under monochromatic blue LED illumination showed values of $Q_{\text {phar }}$ maximum ETR higher than all the remaining treatments.

Kautsky curve analysis (Figure 3a) revealed differences as a progressive decrease in the overall fluorescence from the cultures exposed to RGB LED treatment, Blue LED treatment and the lowest fluorescence values recorded at the cells grown under only red light. These results in differences at the phenomological energy fluxes (Figure 3b). Both monochromatic light treatments resulted in lower values of absorbed (ABS/CS), trapped (TR/CS) and transported (ET/CS) energy fluxes and also lower values of oxidized PSII reaction centers (RC/CS) when compared to the cultures grown under full spectra illumination (RGB LED). Regarding the dissipated energy flux, this was found to be lower in the cultures grown under monochromatic Red LED illumination. If we analyze the number of active oxygen evolving complexes (AOECs, Figure 3c) located at the donor side of the PSII, it is possible to observe that cultures grown under Red LED illumination resulted in an increase number, while the cells grown under monochromatic Blue LED showed a reduction, both when compared to the cultures grown under full spectra illumination (RGB LED).

Fluorescence profiles from the Kautsky curves in a canonical multivariate approach described the differences between treatments (Figure 4). The CAP analysis showed a clear separation of the samples exposed to the different light treatments $(100 \%$ classification efficiency), having as basis its fluorescence profile, supporting the differences abovementioned in terms of Kautsky curves-derived parameters.

\subsection{Pigment Profiles}

The cultures grown under Red LED illumination showed higher contents in chlorophyll $a$ and $c$, Fx, DD and DT (Figure 5a). In comparison with the RGB LED grown cultures, the cells cultured under Blue LED also showed higher chlorophylls $a$ and $c$, DD and DT concentrations. These differences resulted in higher contents of both total chlorophyll (Figure 5 b) and total carotenoids (Figure $5 c$ ) in the cultures exposed to the Red and Blue LED treatments.

Applying these pigment concentrations as a whole pigment profile in a multivariate canonical analysis (Figure 6), it is possible to again efficiently distinguish (93.3\% classification efficiency) the sample groups, grown under different light treatments, highlighting the differences observed at the light-harvesting and photoprotective pigment level. 


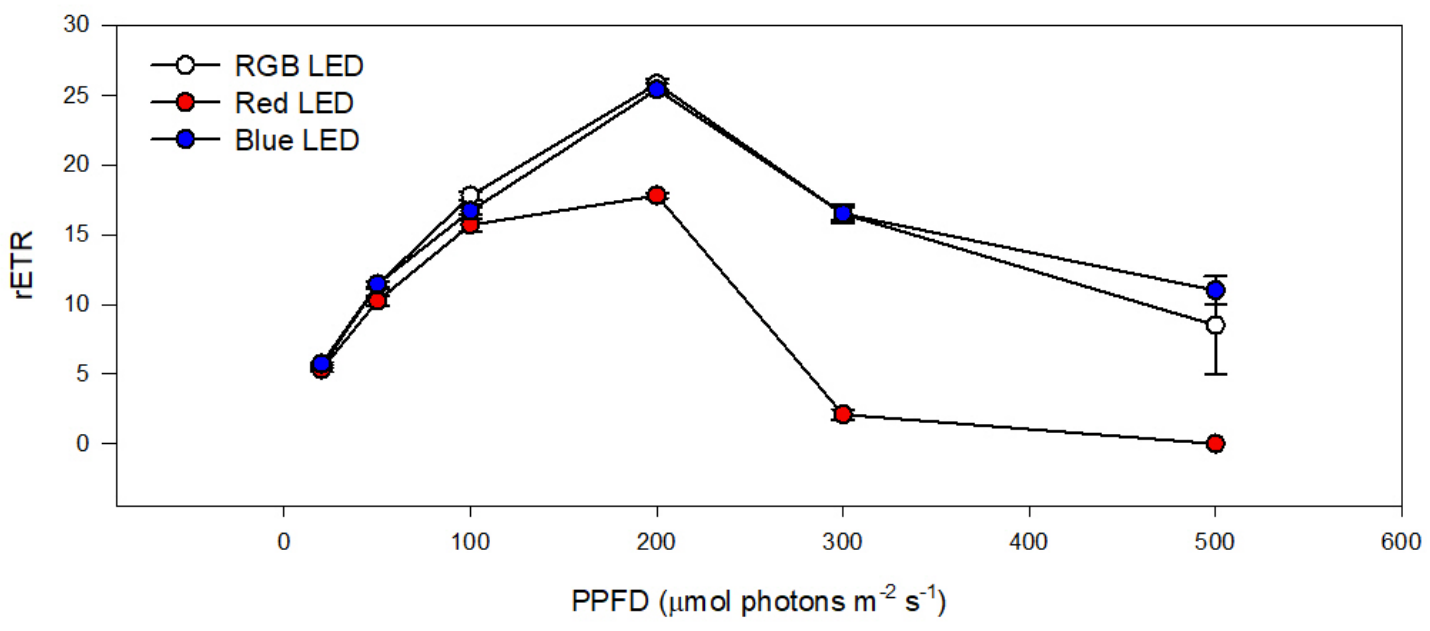

(a)

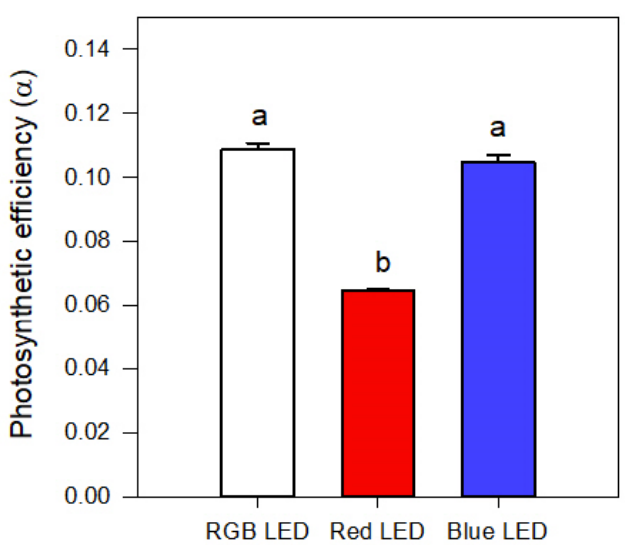

(b)

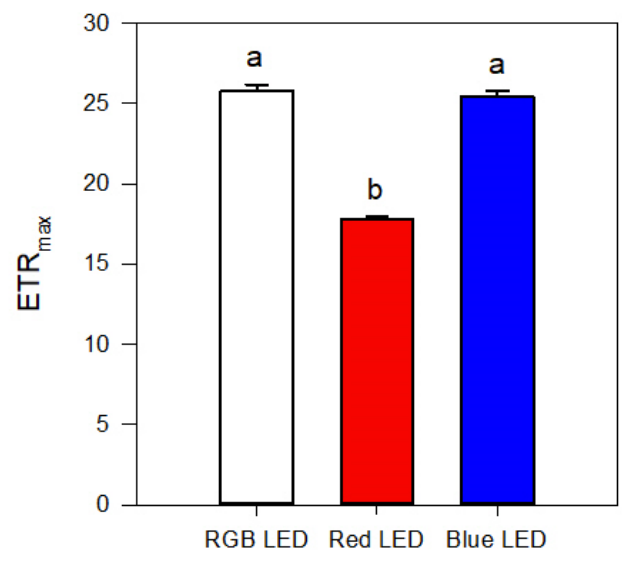

(c)

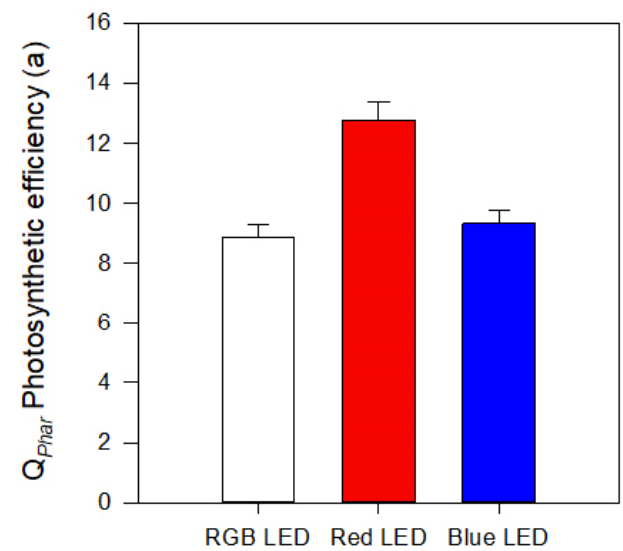

(d)

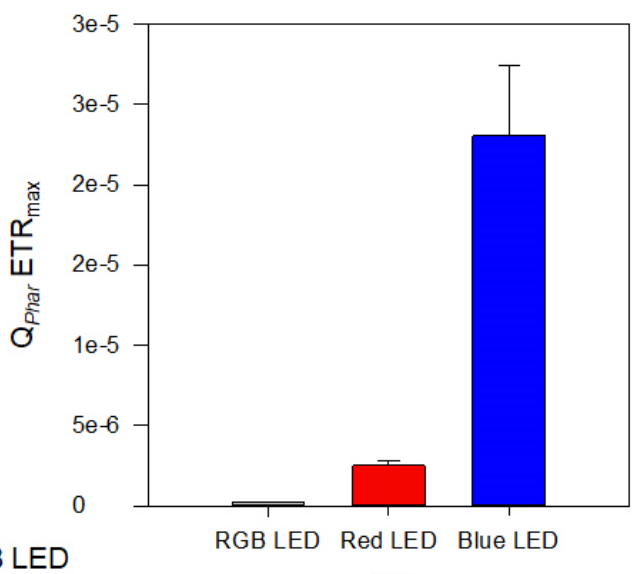

(e)

Figure 2. Rapid light curves (a), photosynthetic efficiency (b) and maximum electron transport rate ((c), ETR max $)$ based on incident photosynthetic photon flux density (PPFD) and in the pigment weighted light absorption ((d), $Q_{\text {Phar }}$ photosynthetic efficiency; (e), maximum electron transport rate $\left.\mathrm{Q}_{\text {Phar }} \mathrm{ETR}_{\max }\right)$ in P. tricornutum cultures $(N=5)$ subjected to the three light treatments at the end of the $96 \mathrm{~h}$ exposure period (average \pm standard error, letters denote significant differences between light treatments at $p<0.05)$. 


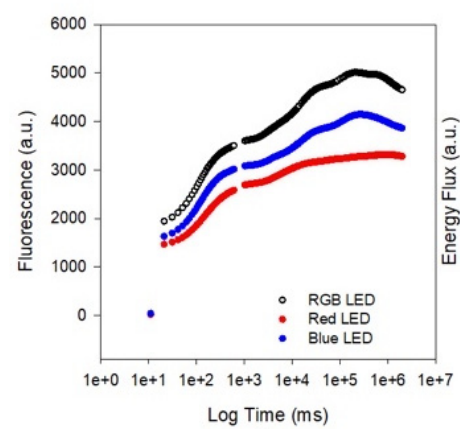

(a)

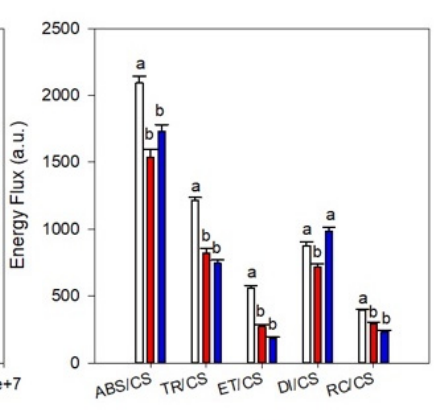

(b)

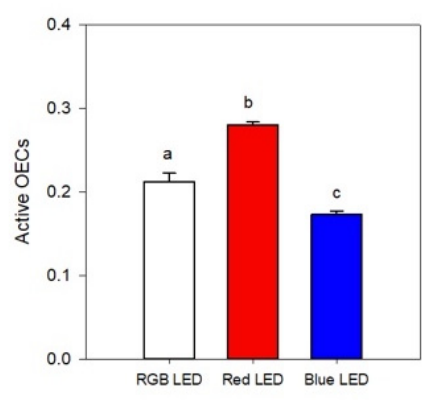

(c)

Figure 3. Kautsky transient light curves (a), phenomological energy fluxes ((b), absorbed (ABS/CS), trapped (TR/CS), transported (ET/CS) and dissipated (DI/CS) energy fluxes and oxidized reaction centers (RC/CS) and active oxygen evolving complexes (c) in the P. tricornutum cultures $(\mathrm{N}=5)$ subjected to the three light treatments at the end of the $96 \mathrm{~h}$ exposure period (average \pm standard error, letters denote significant differences between light treatments at $p<0.05$ ).

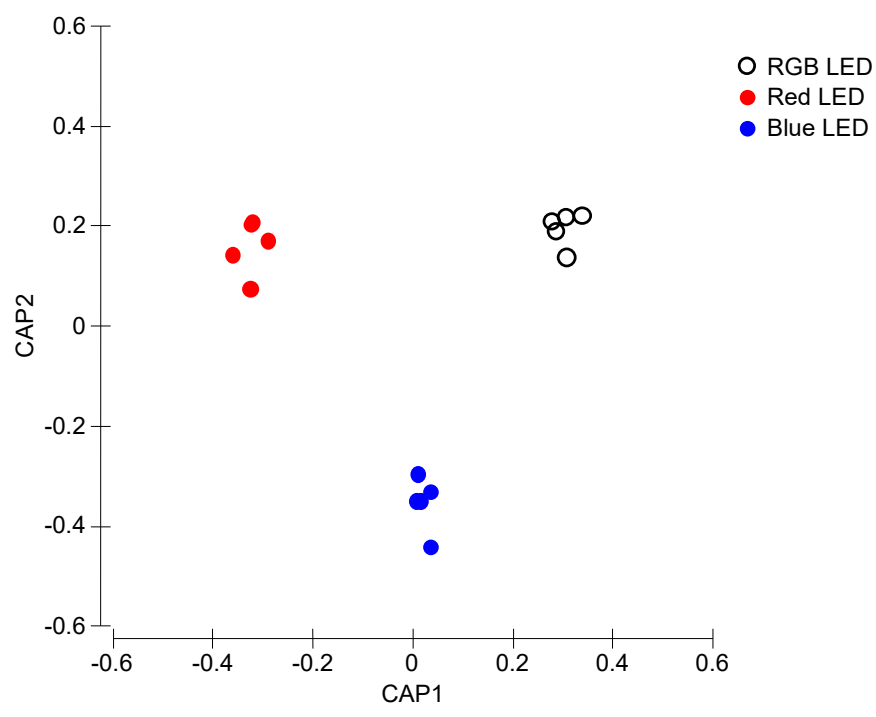

Figure 4. Canonical Analysis of Principal (CAP) components of the P. tricornutum cultures $(N=5)$ subjected to the three light treatments, having as basis the full Kaustky fluorescence profile at the end of the $96 \mathrm{~h}$ exposure period ( $100 \%$ classification efficiency).

\subsection{Total Fatty Acid and TAG Profiles}

The culture of diatoms under Blue LED light resulted in cells with a higher total fatty acid content (Figure 7a). Regarding cells composition in terms of individual fatty acid relative abundance (Figure $7 \mathrm{~b}$ ), the diatom cells grown under Red LED illumination, when compared with the cells cultivated under full light spectrum, showed lower contents of 16:0 (palmitic acid), 16:1 (palmitoleic acid) and 18:4 (stearidonic acid, SDA) fatty acids and higher contents in 16:3 (hexadecatrienoic acid) and 20:5 (eicosapentaenoic acid, EPA). Blue monochromatic LED illumination promoted the production of 16:1 and a decrease of EPA cell content, in comparison with the cultures grown under RGB LED illumination. This fatty acid remodeling resulted in significantly lower saturated fatty acid (SFA) and MUFA contents in the cells grown under monochromatic Red LED illumination, when compared to the cells grown under full spectrum illumination (Figure 7d). Comparing also with the RGB LED exposed cultures, these same cultures presented significantly higher PUFA 
and unsaturated fatty acid (UFA) contents. Regarding the cells cultivated under Blue LED illumination, their PUFA cellular content showed a significant decrease. These alterations combined resulted in differences in IA and IT (Figure 7c).

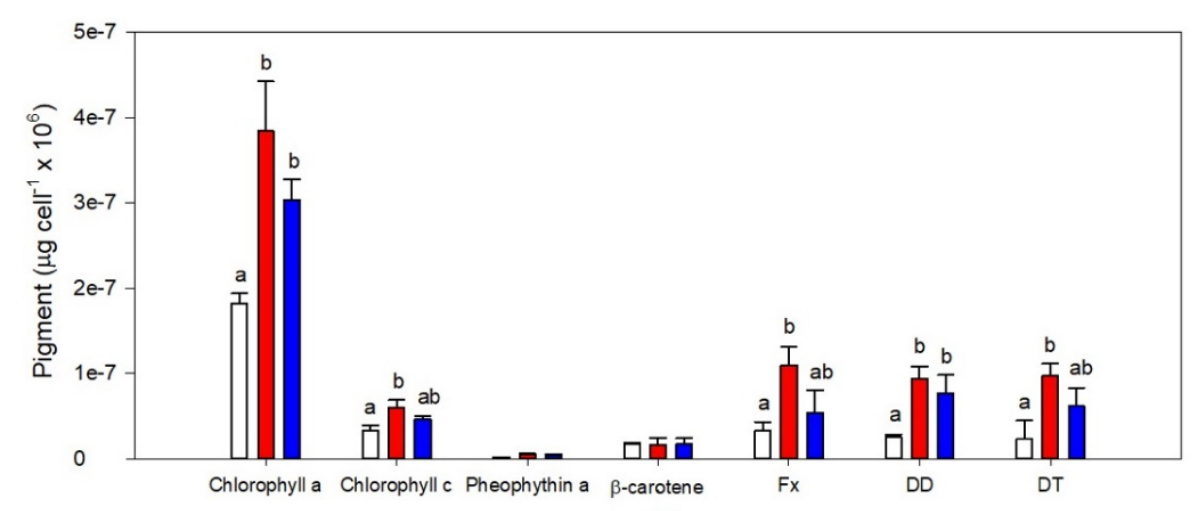

(a)
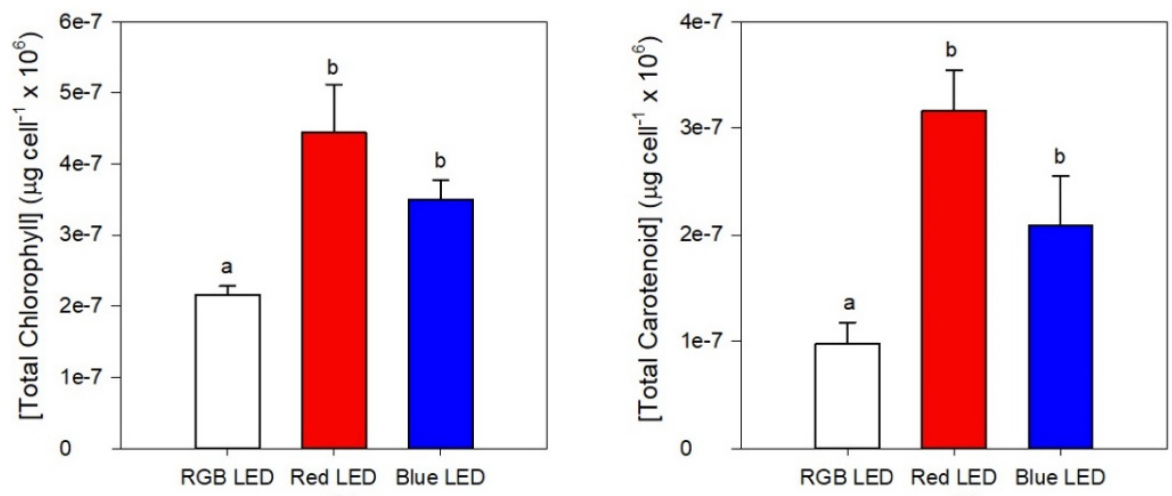

(b)

(c)

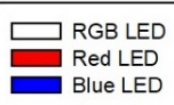

Figure 5. Pigments profiles (a), total chlorophyll (b) and total carotenoids (c) contents of the P. tricornutum cultures $(N=5)$ subjected to the three light treatments at the end of the $96 \mathrm{~h}$ exposure period (average \pm standard error, letters denote significant differences between light treatments at $p<0.05$ ).

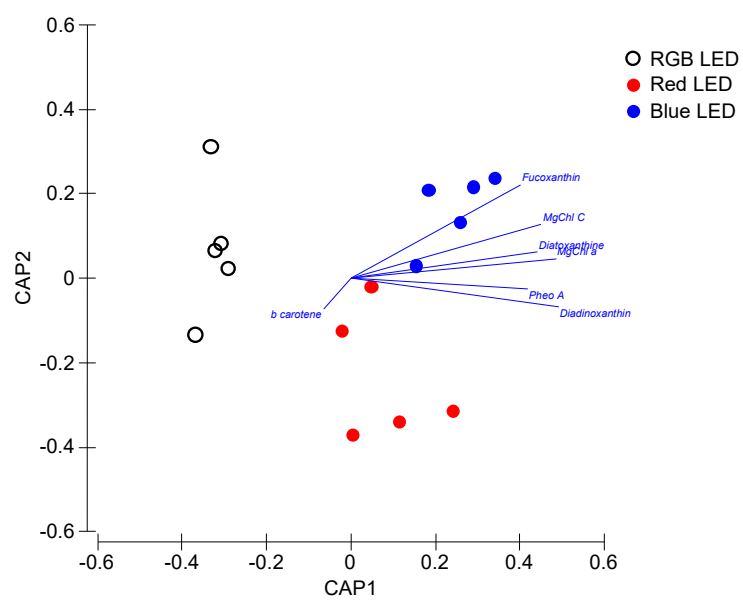

Figure 6. Canonical Analysis of Principal (CAP) components of the P. tricornutum cultures $(N=5)$ subjected to the three light treatments, having as basis the full pigment profile at the end of the $96 \mathrm{~h}$ exposure period ( $93.3 \%$ classification efficiency). 


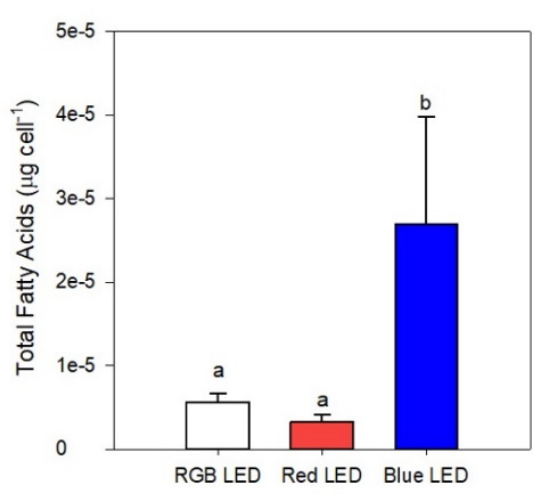

(a)

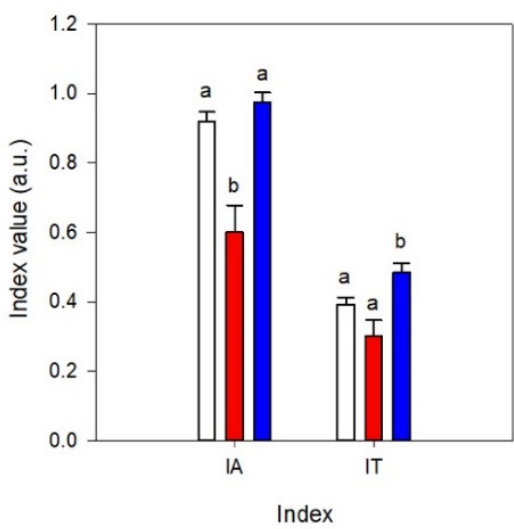

(c)

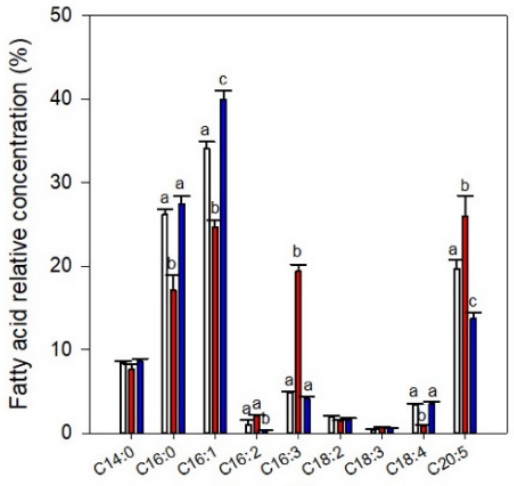

(b)

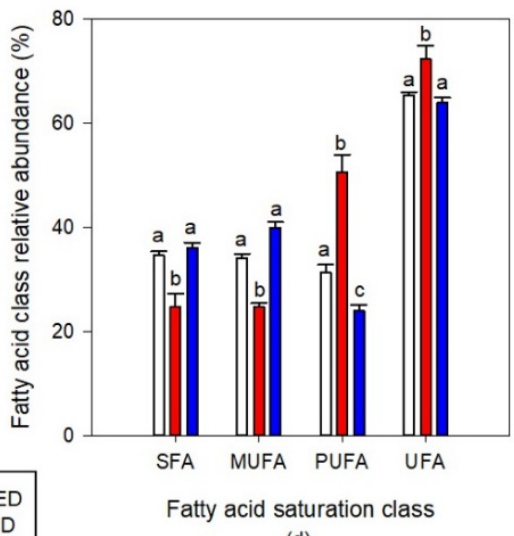

(d)

Figure 7. Total fatty acid content (a) and profile (b), indexes of atherogenicity $(I A)$ and thrombogenicity $(I T)(\mathbf{c})$ and fatty acid unsaturation classes $(\mathbf{d})$ of the $P$. tricornutum cultures $(N=5)$ subjected to the three considered light treatments at the end of the $96 \mathrm{~h}$ exposure period (average \pm standard error, letters denote significant differences between light treatments at $p<0.05$ ).

Regarding the atherogenicity capacity of the cultures in preventing the appearance of micro- and macro-coronary diseases, it was found that the cells grown under monochromatic Red LED illumination are favored in this regard showing a significantly lower $I A$ value, when compared with both RGB and Blue LED exposed cells. On the other hand, blue light exposure seems to favor the thrombogenicity ability of the culture's fatty acid profile, presenting a higher IT value.

As previously computed for the photochemical and pigment data, the fatty acid profiles of the samples were also analyzed in a multivariate canonical approach in order to evaluate if these fatty acid traits are efficient descriptors of the cells culture light conditions (Figure 8). Once again, a clear separation of the samples grown under different light qualities is observed, with the overall canonical analysis presenting a classification efficiency of the samples of $93.3 \%$, having as basis the cells fatty acid profiles. 


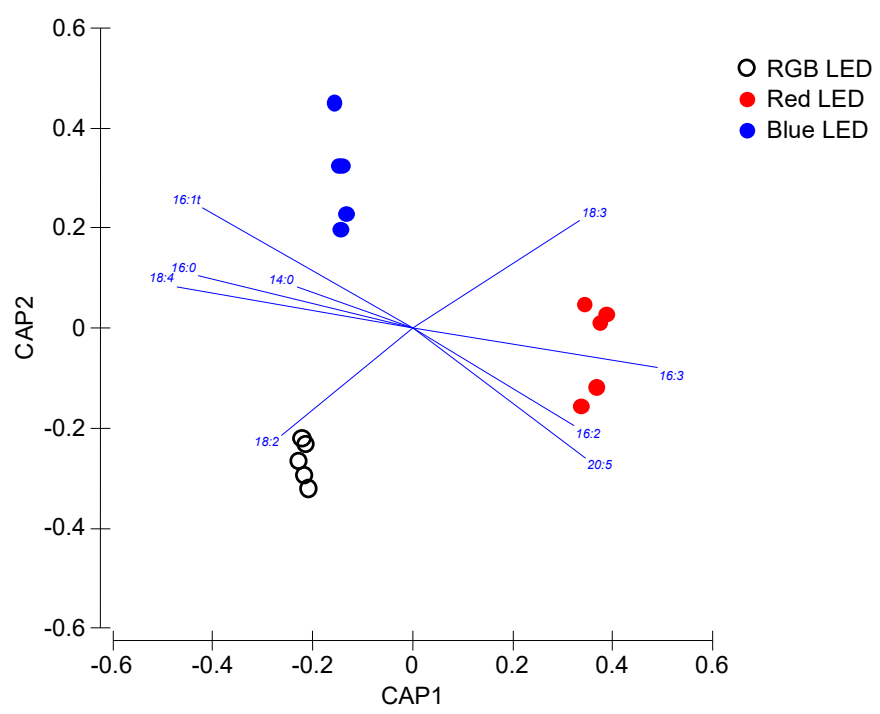

Figure 8. Canonical Analysis of Principal (CAP) components of the P. tricornutum cultures $(N=5)$ subjected to the three light treatments, having as basis the total fatty acid profile (relative concentrations) at the end of the $96 \mathrm{~h}$ exposure period ( $93.3 \%$ classification efficiency).

Regarding the TAG fatty acid profile, the different light qualities to which the cultures were subjected also induced some significant differences (Figure 9a). The TAG fatty acid profile of the cultures grown under monochromatic Red LED illumination showed significantly lower values of 14:0 (myristic acid), 16:0, and 16:1 fatty acid relative concentration and significantly higher concentrations of 16:3 (hexadecadienoic acid) and EPA fatty acids. Cultures grown under Blue LED illumination on the other hand showed a significant increase in the TAG concentration of 18:2 (linoleic acid), 18:3 ( $\gamma$-linolenic acid, GLA) and 18:4. This had inevitable results in the saturation classes of the fatty acid profile of the TAG of the cells cultured at different light conditions (Figure 9b). Significant differences could only be observed in the cells cultured under Red LED illumination, with higher concentration of PUFA and lower contents of TAG SFA and MUFA in TAG, when compared to the cells cultured under RGB LED illumination. Regarding the TAG cellular content (Figure 9c), this was found to be significantly reduced by the cultivation of the diatom cells under Red LED illumination. In addition, considering the changes above reported regarding the total fatty acids content, the TAG relative content when compared to the total fatty acid in the cells cultivated under red and blue LED illumination decreased to $0.7 \%$ and $2.6 \%$ respectively versus $5.2 \%$ observed in the cells cultured under RGB LED illumination.

Nevertheless, the slight differences observed, the TAG fatty acid profile also proved to efficiently discriminate ( $100 \%$ classification accuracy) the cultures cultivated under different light qualities, indicating that this TAG fatty acid profile is specific of the light used for diatom cultivation and thus can be modified by the illumination wavelength range (Figure 10). 


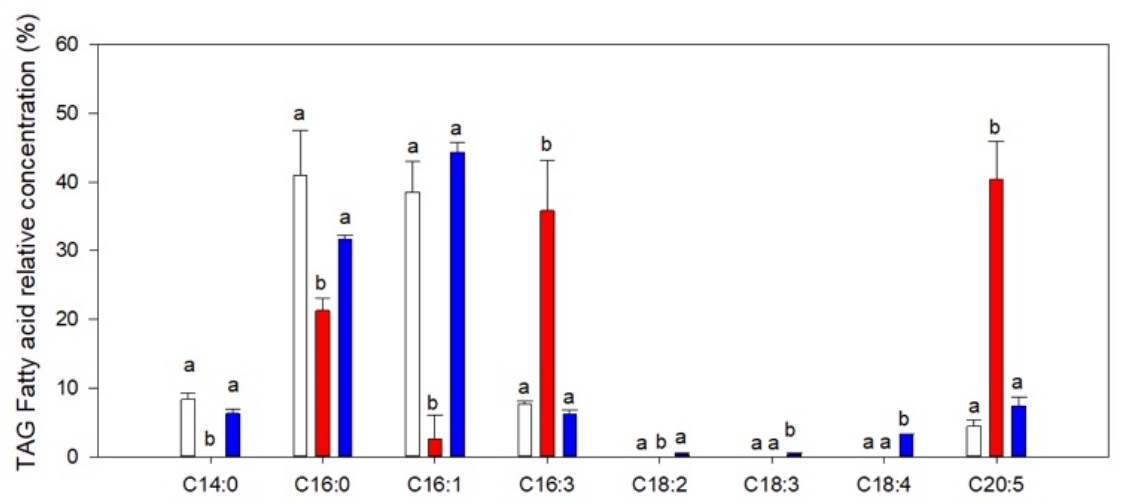

(a)
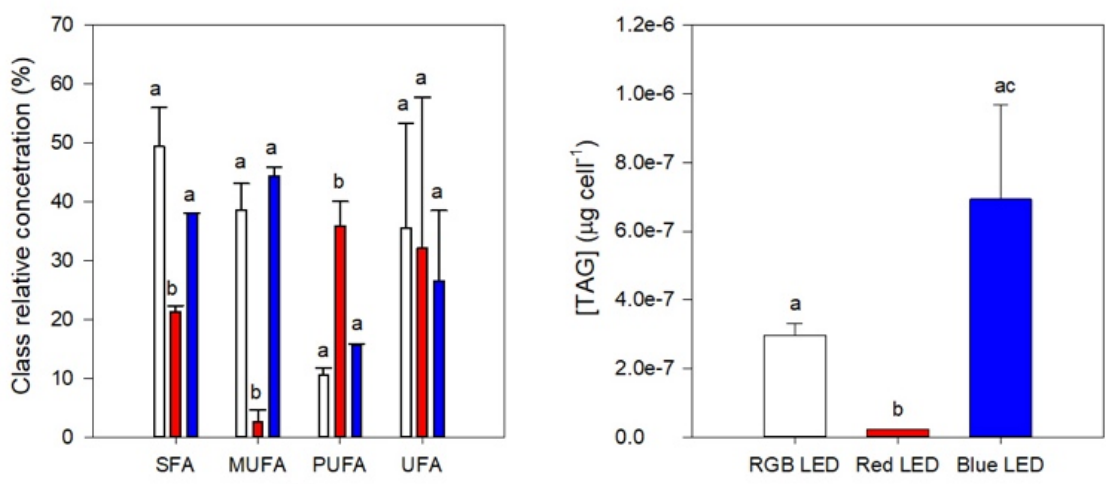

(b)

(c)

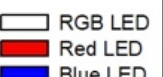

Blue LED

Figure 9. TAG fatty acid profile (a) saturation classes (b) and cellular content (c) of the P. tricornutum cultures $(N=3)$ subjected to the three light treatments at the end of the $96 \mathrm{~h}$ exposure period (average \pm standard error, letters denote significant differences between light treatments at $p<0.05$ ).

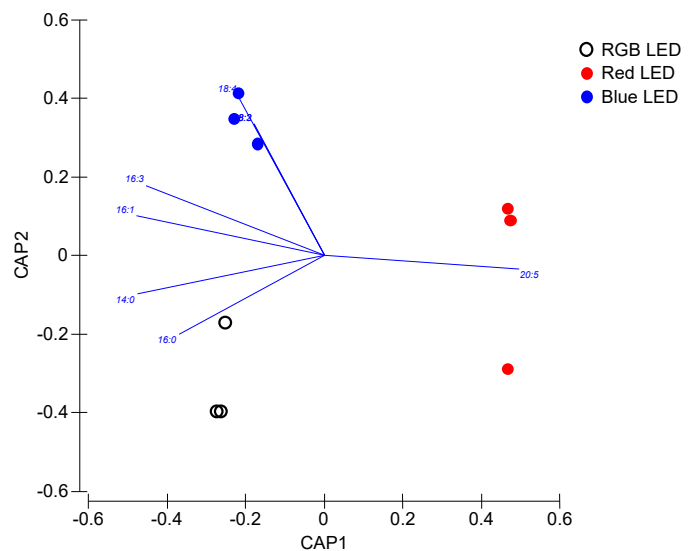

Figure 10. Canonical Analysis of Principal (CAP) components of the P. tricornutum cultures $(N=5)$ subjected to the three light treatments, having as basis the TAG fatty acid profile (relative concentrations) at the end of the $96 \mathrm{~h}$ exposure period (100\% classification efficiency).

\section{Discussion}

Diatoms have been suggested as potential high value molecule suppliers for nutraceutical, fuel and aquaculture sectors, by providing bioenergy, food and feed and as supporter of wastewater bioremediation [3]. They are fast growing organisms and require 
low cultivation conditions while offering high process turnover and economically viable processing alternatives [2]. The current study reports that pigment and fatty acid profiles in the model diatom Phaeodactylum tricornutum can be modulated based on different spectral light regimes supplied through LEDs without limiting cell division rates.

At this level, the application of RGB LED illumination versus red and Blue LED illuminations did not lead to different cell densities at the end of the $96 \mathrm{~h}$ culture period. Such similarity in cell density at the end of the culture trials might be due to the nutritional limitation in the late phase of the culture, regarded to the high division rates common in the species P. tricornutum [41]. However, cultures exposed to red LED illumination presented a faster growth during the first $48 \mathrm{~h}$, indicating a potential role of the light conditions for exponential phase cell growth enhancement. As all light treatments were adjusted to the same total photon flux rates, increased growth during the first days of culture may therefore indicate improved light harvesting under Red LED illumination. Previous studies showed an enhancement of microalgae cell growth cultured under blue light illumination [42] due to higher photosynthetic electron transport, while blue light may also induce higher nonphotochemical quenching [43]. Although most diatom pigments have higher absorption rates for shorter wavelength of light (blue light), at this level no higher growth rates were observed, indicating that given photon flux densities were sufficient to obtain maximum cell density growth. Excessive energy might then be dissipated along the photosynthetic transport chain, limiting accumulation of biomass [44]. When photosynthetic efficiencies are compared to RGB illumination, no apparent differences occur at the end of the experiment. However, when cell growth is compared based on pigment weighted light absorption, some differences become obvious. The cells grown under red LED illumination have higher $\mathrm{Q}_{\text {phar }}$ photosynthetic efficiency concomitant with the higher growth rates as observed during the first $48 \mathrm{~h}$. This is due to the differences in the light absorption of the different pigment profiles originating from the different light quality exposure. This might be due to the high chlorophyll $a$ content, a pigment with a high absorption coefficient at $627 \mathrm{~nm}$ (equals red LED dominant wavelength) [30]. In terms of phenomenological energy fluxes the cells grown under red LED illumination showed a reduction in all energy fluxes in a proportional manner, indicating that there is a higher efficiency in the incident light-use. This was in fact previously reported [17], where $P$. tricornutum cells grow under red light showed lower nonphotochemical quenching (lower energy dissipation) and thus higher light-use efficiencies per incident photon. This is also in accordance with the higher dissipated energy flux rates (concomitant with higher nonphotochemical quenching, as reported in [17]) observed in the cells grown under Blue LED illumination. A possible explanation for the observed similar cell densities at the end of the trials under different LED regimes was also reported in the centric diatom Coscinodiscus granii, pointing towards illumination conditions supporting maximum diatom cell growth [45]. In sum, in photochemical terms, cells are not substantially affected by the different illumination conditions at the end of the experiment, under the given nutrient conditions and PPFD availabilities. However, it is important to point out that, according to our data, a culture medium may replenish with nutrients at the end of $48 \mathrm{~h}$, as indicated by higher exponential growth under red illumination in the beginning of the trial.

In terms of fatty acid and TAG accumulation, cell cultures under Blue LED light exhibited high total fatty acid and TAG concentrations. This high accumulation of lipids was already reported before, in the diatom Skeletonema marinoi [46], pointing out an effective energy and carbon storage strategy [47]. The increase in storage lipids such as TAG, under high frequency blue light has also been attributed to their role in preventing photooxidative damages [48]. In fact, and as abovementioned, the cultures subjected to Blue LED illumination showed higher dissipated energy fluxes, also indicative of the need to dissipate excessive energy, another strategy to prevent photo-inhibition.

In terms of bioenergy production, the results also have a relevant role. High amounts of SFAs provide a superior oxidative stability, while PUFAs provide better cold-flow properties at the cost of oxidative stability [49]. Examining the saturation degree of the 
different cultures, two important characteristics were evident. Both in terms of whole fatty acid and TAG contents, the cells grown under red LED illumination presented a high content in PUFA, i.e., higher cold-flow properties. These cultures also showed another important feature in terms of bioenergy production. The fatty acid saturation degree was linearly correlated to the cetane number $(\mathrm{CN})$, a fuel quality parameter which is related to ignition delay and combustion quality of the fuels [49]. At this level also the cells grown under red light illumination showed a substantially higher UFAs percentage, reinforcing the promising characteristics of the fatty acids produced under these experimental conditions. Cultures subjected to blue light illumination presented a higher fatty acid content and in terms of quality for bioenergy applications presented higher saturation degree and thus better characteristics for biodiesel production.

Some nutritional characteristics can also be highlighted for the fatty acid profiles produced under the different light qualities. As abovementioned two indices can be used to evaluate the potential role of certain fatty acid profiles for human health: the $I A$ value is related to the plaque formation and to the decrease in the levels of esterified fatty acid, cholesterol, and phospholipids, thereby preventing the appearance of micro- and macro-coronary diseases [33]; the IT value is related to the tendency to form clots in the blood vessels [33]. Since saturated FAs are considered to be proatherogenic and UFAs antiatherogenic, a low $I A$ ratio is recommended [33]. Regarding IT, this index indicates the propensity to form masses in the blood vessels and is defined as the relationship between the prothrombogenic (saturated fatty acids) and the antithrombogenic MUFA, n-3 and n-6 PUFA). Therefore, a low IT value is also desirable [33]. Tuna, a fish considered to have a high nutritional value in terms of its fatty acid profile, has an IA and IT of approximately 0.7 and 0.3 , respectively [33], and is therefore used as a reference. At this level, the cultures grown under red wavelength illumination present a better nutritional quality, with very low IA and IT values. Moreover, red illumination promoted the accumulation of PUFAs, namely EPA. This fatty acid intake has significant improvements in terms of human health, improving the vascular and neural health $[50,51]$. Moreover, considering that a large fraction of the developed countries population presents a very low intake of EPA and that the largest source of this PUFA is fish intake, another aspect that is highly reduced in western populations, this EPA content acquires a reinforced role as a possible alternative source of these key fatty acids $[50,51]$. Biosynthesis of EPA is thought to occur in the endoplasmic reticulum via two complementary pathways [52]. In the $\omega-3$ pathway $\alpha$-Linolenic acid (18:3, ALA) is desaturated to 18:4 which suffers subsequent elongation to 20:4, while in the $\omega-6$ pathway 18:2 is desaturated to GLA and subsequently elongated to eicosatrienoic acid (20:3, ETA) and desaturated to 20:4. A $\Delta 5$-desaturase is reported to act in both pathways, converting 20:3 to 20:4 in the $\omega-6$ pathway, and 20:4 to EPA in the $\omega-3$ pathway [52,53]. Overall, cultures grown under red light revealed increased abundance of 16:3 and EPA, a trend which was also reflected in the TAG composition. It is possible that red light induced recycling of plastidal membrane fatty acids through phospholipase A activity given the increased abundance of 16:3 in TAG [54]. The overall increase in C16 fatty acids, namely 16:2 and 16:3, could suggest variations in lipid classes such as monogalactosyldiacylglycerol (MGDG) and digalactosyldiacylglycerol (DGDG), responsible for fucoxanthin chlorophyll proteins (FCP) stabilization and electron transport [55]. The decreased abundance of 18:4 in cultures grown under red illumination could also suggest a prominence of $\Delta 6$-elongase activity or gene expression in the $\omega-3$ pathway converting 18:4 to $20: 4$, rather than GLA to ETA in the $\omega-6$ pathway, and increased $\Delta 5$-desaturase activity, resulting in the observed EPA increase. Blue light induced an increase of 16:1 and decrease in EPA content overall; however, the major changes in TAG composition were observed in C18 fatty acids. In sum, cultures grown under red LED illumination presented a high concentration of chloroplastidal fatty acids and long chain PUFAs, while blue light-growth induced the accumulation of EPA precursors in TAG (Figure 11). These results could imply an interaction between light quality, photoreceptors and regulation of genes involved in the lipid and fatty acid metabolism. It is interesting to notice that stearidonic acid, a precursor of EPA with known 
significant health promoting effects [56], also had its concentration increased in the cultures grown under blue light illumination. In sum, cultures grown under red LED illumination presented a high concentration of long-chain fatty acids, while blue light-growth induced the accumulation of its precursors (Figure 11).
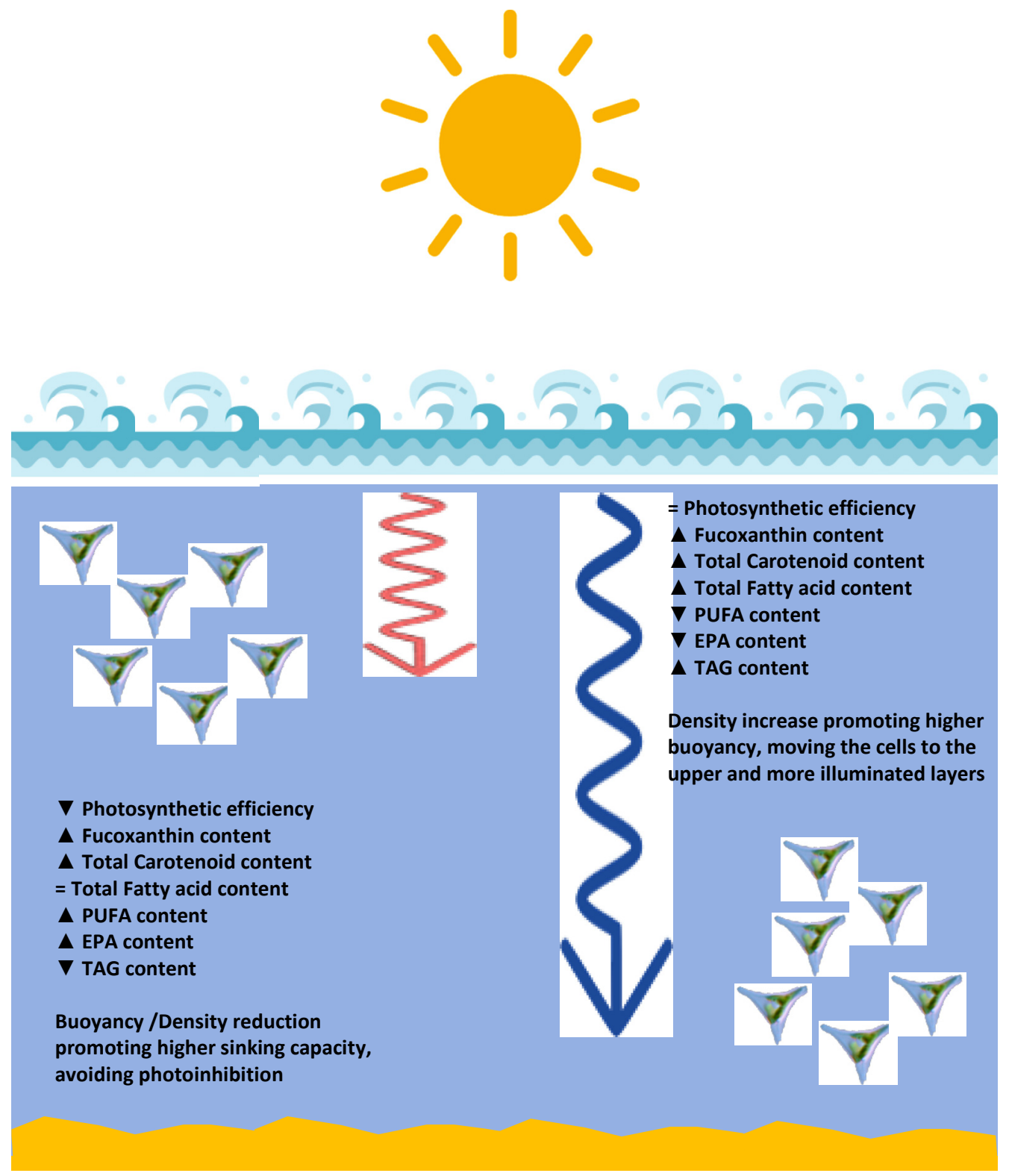

Figure 11. Schematic model of the metabolic changes induced by different wavelengths reaching the different depth layers of the ocean water column (blue and red arrows represent the penetration capacity of the red and blue wavelengths, respectively).

Another group of interesting value-added products produced by marine diatoms are the carotenoids with relevant applications for biotechnology and human health as nutraceuticals $[57,58]$. From the wide array of pigments produced by diatoms some like $\beta$ -carotene and Fx have been widely investigated and targeted in studies aiming to enhance its production in microalgae cultures $[2,57,58]$. Generally speaking, carotenoid pigment production is related to local environmental conditions (such as light conditions and nutrient availability). Fucoxanthin, chlorophyll $a$ and $c$ are the main light-harvesting pigments in diatoms, whereas $\beta$-carotene, DD and DT are mainly involved in photoprotection mech- 
anisms [45]. Regarding the potential nutritional aspects of carotenoids produced these also highlight the potential application of red and blue illumination for improving $P$. tricornutum nutraceutical value. $\beta$-carotene is typically the most abundant carotenoid in plants, presenting a recognized antioxidant value, associated with a reduced risk of several diseases including cardiovascular disease [59]. This comes largely from the ability of this pigment to act as a reactive oxygen species (ROS) scavenger [59]. The increase in the pool of $\beta$-carotene, precursor of all the other carotenoids, also allows the increased production of other carotenoids such as Fx. Fucoxanthin is a pigment mainly found in brown seaweed and Bacillariophyta (diatoms) [60], and thus any reinforcement in its production is of value-added for industry purposes. This carotenoid has known antioxidant, antiobesity, antidiabetic and anticancer activities [60]. At this level Red LED illumination had a higher effect in the per cell content of this carotenoid, but yet both Blue and Red LED treatments are able to improve diatom Fx production. However, based on the data we conclude that both LED treatments are equally efficient in inducing carotenoid production.

Some similarities observed from the pigment profiles under red and blue light exposed cultures can result from diatom adaptation to the marine environment at different water column depths and are consistent with other studies on phytoplankton [61,62] (Figure 11). In the marine environment, under oligotrophic conditions, light in the blue-green and red spectrum are dominant at higher and lower depths, respectively [63]. Longer wavelengths of the visible light spectrum commonly attenuate faster in water. In consequence, proportions of the red spectral range of light might be higher at subsurface layers where light intensities are higher. Based on the results presented in this study, we propose that diatoms at subsurface layers perceive higher proportions of blue light, inducing less unsaturated TAG remobilization to increase their density and buoyancy. In contrast, diatoms at surface layers might perceive high light flux rates, potentially causing oxidative stress and photodamage. In consequence, carotenoid based photoprotective mechanisms are induced, and the photosynthetic activity is reduced, while cellular energy is dissipated through the consumption of lipid reserves (TAG) leading to reduced cell density and buoyancy reduction. We therefore propose that the proportion of red to blue light are sensed by the diatom cell, either via photoreceptors and/or by physiological feedback loops of the light absorbing and photosynthetic apparatuses (Figure 11) [64]. However, given the complex and diverse light environments in aquatic habitats [15], this proposed mechanisms is speculative and requires further investigation and validation in other planktonic diatom species. Deeper investigation into the natural conditions of light availability in diatom inhabited environments, both in intensity and spectral light composition, may result in better understanding of the apparent complex interplay of cellular light absorption, light perception, photosynthetic activity and other cellular adaptation mechanisms. We propose that such mechanisms may be hijacked for an environmentally friendly production of particular high value products by diatoms, to foster a more sustainable economy in future.

Author Contributions: Conceptualization, J.W.G. and B.D.; investigation, B.D and E.F.; resources, A.R.M.; writing—original draft preparation, B.D.; writing—review and editing, J.W.G., A.R.M., I.C. and E.F.; supervision, A.R.M. and I.C. All authors have read and agreed to the published version of the manuscript.

Funding: The authors would like to thank Fundação para a Ciência e a Tecnologia (FCT) for funding the research via project grants PTDC/CTA-AMB/30056/2017 (OPTOX), UIDB/04292/2020, UIDB/04046/2020. B. Duarte was supported by an investigation contract (CEECIND/00511/2017).

Institutional Review Board Statement: Not applicable.

Informed Consent Statement: Not applicable.

Data Availability Statement: The data presented in this study are available on request from the corresponding author. The data are not publicly available due to being part of an ongoing project.

Conflicts of Interest: The authors declare no conflict of interest. 


\section{References}

1. Falkowski, P.G.; Laws, E.A.; Barber, R.T.; Murray, J.W. Phytoplankton and Their Role in Primary, New, and Export Production. In Ocean Biogeochemistry; Fasham, M.J.R., Ed.; Springer: Berlin/Heidelberg, Germany, 2003; pp. 99-121. ISBN 978-3-642-55844-3.

2. Butler, T.; Kapoore, R.V.; Vaidyanathan, S. Phaeodactylum tricornutum: A Diatom Cell Factory. Trends Biotechnol. 2020, 38, 606-622. [CrossRef]

3. Richmond, A.; Hu, Q. Handbook of Microalgal Culture; Richmond, A., Hu, Q., Eds.; John Wiley \& Sons, Ltd: Oxford, UK, 2013; ISBN 9781118567166.

4. Kroth, P. Molecular Biology and the Biotechnological Potential of Diatoms. In Transgenic Microalgae as Green Cell Factories; León, R., Galván, A., Fernández, E., Eds.; Springer: New York, NY, USA, 2007; pp. 23-33. ISBN 978-0-387-75532-8.

5. $\quad$ Lima, S.; Schulze, P.S.C.; Schüler, L.M.; Rautenberger, R.; Morales-Sánchez, D.; Santos, T.F.; Pereira, H.; Varela, J.C.S.; Scargiali, F.; Wijffels, R.H.; et al. Flashing light emitting diodes (LEDs) induce proteins, polyunsaturated fatty acids and pigments in three microalgae. J. Biotechnol. 2021, 325, 15-24. [CrossRef]

6. Vúlchez, C.; Forján, E.; Cuaresma, M.; Bédmar, F.; Garbayo, I.; Vega, J.M. Marine Carotenoids: Biological Functions and Commercial Applications. Mar. Drugs 2011, 9, 319-333. [CrossRef] [PubMed]

7. Fu, W.; Wichuk, K.; Brynjólfsson, S. Developing diatoms for value-added products: Challenges and opportunities. New Biotechnol. 2015, 32, 547-551. [CrossRef]

8. Xiang, S.; Liu, F.; Lin, J.; Chen, H.; Huang, C.; Chen, L.; Zhou, Y.; Ye, L.; Zhang, K.; Jin, J.; et al. Fucoxanthin Inhibits $\beta$-Amyloid Assembly and Attenuates $\beta$-Amyloid Oligomer-Induced Cognitive Impairments. J. Agric. Food Chem. 2017, 65, 4092-4102. [CrossRef] [PubMed]

9. Peng, J.; Yuan, J.-P.; Wu, C.-F.; Wang, J.-H. Fucoxanthin, a marine carotenoid present in brown seaweeds and diatoms: Metabolism and bioactivities relevant to human health. Mar. Drugs 2011, 9, 1806-1828. [CrossRef] [PubMed]

10. Guschina, I.A.; Harwood, J.L. Lipids and lipid metabolism in eukaryotic algae. Prog. Lipid Res. 2006, 45, 160-186. [CrossRef] [PubMed]

11. Shahidi, F.; Ambigaipalan, P. Omega-3 Polyunsaturated Fatty Acids and Their Health Benefits. Annu. Rev. Food Sci. Technol. 2018, 9, 345-381. [CrossRef]

12. Hildebrand, M.; Davis, A.K.; Smith, S.R.; Traller, J.C.; Abbriano, R. The place of diatoms in the biofuels industry. Biofuels 2012, 3, 221-240. [CrossRef]

13. Blanken, W.; Cuaresma, M.; Wijffels, R.H.; Janssen, M. Cultivation of microalgae on artificial light comes at a cost. Algal Res. 2013, 2, 333-340. [CrossRef]

14. Stomp, M.; Huisman, J.; Stal, L.J.; Matthijs, H.C.P. Colorful niches of phototrophic microorganisms shaped by vibrations of the water molecule. ISME J. 2007, 1, 271-282. [CrossRef] [PubMed]

15. Kirk, J.T.O. Light and Photosynthesis in Aquatic Ecosystems, 3rd ed.Cambridge University Press: Cambridge, UK, 2010; ISBN 9780521151757.

16. Shikata, T.; Nukata, A.; Yoshikawa, S.; Matsubara, T.; Yamasaki, Y.; Shimasaki, Y.; Oshima, Y.; Honjo, T. Effects of light quality on initiation and development of meroplanktonic diatom blooms in a eutrophic shallow sea. Mar. Biol. 2009, 156, 875-889. [CrossRef]

17. Jungandreas, A.; Costa, B.S.; Jakob, T.; von Bergen, M.; Baumann, S.; Wilhelm, C. The Acclimation of Phaeodactylum tricornutum to Blue and Red Light Does Not Influence the Photosynthetic Light Reaction but Strongly Disturbs the Carbon Allocation Pattern. PLoS ONE 2014, 9, e99727. [CrossRef]

18. Herbstová, M.; Bína, D.; Kaňa, R.; Vácha, F.; Litvín, R. Red-light phenotype in a marine diatom involves a specialized oligomeric red-shifted antenna and altered cell morphology. Sci. Rep. 2017, 7, 11976. [CrossRef] [PubMed]

19. Guillard, R.R.L.; Ryther, J.H. Studies of Marine Planktonic Diatoms: I. Cyclotella Nana Hustedt, and Detonula Confervacea (Cleve) Gran. Can. J. Microbiol. 1962, 8, 229-239. [CrossRef] [PubMed]

20. Feijão, E.; Gameiro, C.; Franzitta, M.; Duarte, B.; Caçador, I.; Cabrita, M.T.; Matos, A.R. Heat wave impacts on the model diatom Phaeodactylum tricornutum: Searching for photochemical and fatty acid biomarkers of thermal stress. Ecol. Indic. 2018, 95, 1026-1037. [CrossRef]

21. OECD Guidelines for the Testing of Chemicals. Freshwater Alga and Cyanobacteria, Growth Inhibition Test. Organ. Econ. Coop. Dev. 2011, 1-25.

22. Tachi, N.; Hashimoto, Y.; Ogino, N. Vitrectomy for macular edema combined with retinal vein occlusion. Doc. Ophthalmol. 1999, 97, 465-469. [CrossRef]

23. Srivastava, A.; Strasser, R.J. Survival strategies of plants to cope with the stress of daily atmospheric changes. In Crop Improvement for Food Security; Behl, R.K., Punia, M.S., Lather, B.P.S., Eds.; SSARM: Hisar, Idina, 1999; pp. 60-71.

24. Strasser, R.J.; Tsimilli-Michael, M.; Srivastava, A. Analysis of the fluorescence transient. In Chlorophyll Fluorescence: A Signature of Photosynthesis. Advances in Photosynthesis and Respiration Series; Papageorgiou, G.C., Govindjee, Eds.; Springer: Dordrecht, The Netherlands, 2004; pp. 321-362.

25. Cabrita, M.T.; Duarte, B.; Gameiro, C.; Godinho, R.M.; Caçador, I. Photochemical features and trace element substituted chlorophylls as early detection biomarkers of metal exposure in the model diatom Phaeodactylum tricornutum. Ecol. Indic. 2018, 95, 1038-1052. [CrossRef] 
26. Cabrita, M.T.; Gameiro, C.; Utkin, A.B.; Duarte, B.; Caçador, I.; Cartaxana, P. Photosynthetic pigment laser-induced fluorescence indicators for the detection of changes associated with trace element stress in the diatom model species Phaeodactylum tricornutum. Environ. Monit. Assess. 2016, 188, 285. [CrossRef]

27. Küpper, H.; Seibert, S.; Parameswaran, A. Fast, sensitive, and inexpensive alternative to analytical pigment HPLC: Quantification of chlorophylls and carotenoids in crude extracts by fitting with Gauss peak spectra. Anal. Chem. 2007, 79, 7611-7627. [CrossRef]

28. Prins, A.; Deleris, P.; Hubas, C.; Jesus, B. Effect of Light Intensity and Light Quality on Diatom Behavioral and Physiological Photoprotection. Front. Mar. Sci. 2020, 7. [CrossRef]

29. Gilbert, M.; Domin, A.; Becker, A.; Wilhelm, C. Estimation of Primary Productivity by Chlorophyll a in vivo Fluorescence in Freshwater Phytoplankton. Photosynthetica 2000, 38, 111-126. [CrossRef]

30. Clementson, L.A.; Wojtasiewicz, B. Dataset on the absorption characteristics of extracted phytoplankton pigments. Data Br. 2019, 24, 103875. [CrossRef] [PubMed]

31. Matos, A.R.; Hourton-Cabassa, C.; Ciçek, D.; Rezé, N.; Arrabaça, J.D.; Zachowski, A.; Moreau, F. Alternative oxidase involvement in cold stress response of Arabidopsis thaliana fad2 and FAD3 ${ }^{+}$cell suspensions altered in membrane lipid composition. Plant Cell Physiol. 2007, 48, 856-865. [CrossRef] [PubMed]

32. Duarte, B.; Prata, D.; Matos, A.R.; Cabrita, M.T.; Caçador, I.; Marques, J.C.; Cabral, H.N.; Reis-Santos, P.; Fonseca, V.F. Ecotoxicity of the lipid-lowering drug bezafibrate on the bioenergetics and lipid metabolism of the diatom Phaeodactylum tricornutum. Sci. Total Environ. 2019, 650, 2085-2094. [CrossRef]

33. Garaffo, M.A.; Vassallo-Agius, R.; Nengas, Y.; Lembo, E.; Rando, R.; Maisano, R.; Dugo, G.; Giuffrida, D. Fatty Acids Profile, Atherogenic (IA) and Thrombogenic (IT) Health Lipid Indices, of Raw Roe of Blue Fin Tuna (Thunnus thynnus L.) and Their Salted Product "Bottarga". Food Nutr. Sci. 2011, 2, 736-743.

34. Lee, H.Y.; Bahn, S.C.; Kang, Y.-M.M.; Lee, K.H.; Kim, H.J.; Noh, E.K.; Palta, J.P.; Shin, J.S.; Ryu, S.B. Secretory Low Molecular Weight Phospholipase A 2 Plays Important Roles in Cell Elongation and Shoot Gravitropism in Arabidopsis. Plant Cell 2003, 15, 1990-2002. [CrossRef] [PubMed]

35. Matos, A.R.A.R.; Gigon, A.; Laffray, D.; Pêtres, S.; Zuily-Fodil, Y.; Pham-Thi, A.-T. Effects of progressive drought stress on the expression of patatin-like lipid acyl hydrolase genes in Arabidopsis leaves. Physiol. Plant. 2008, 134, 110-120. [CrossRef]

36. Laureano, G.; Figueiredo, J.; Cavaco, A.R.; Duarte, B.; Caçador, I.; Malhó, R.; Silva, M.S.; Matos, A.R.; Figueiredo, A. Author Correction: The interplay between membrane lipids and phospholipase A family members in grapevine resistance against Plasmopara viticola. Sci. Rep. 2019, 9, 6731. [CrossRef] [PubMed]

37. Duarte, B.; Pedro, S.; Marques, J.C.; Adão, H.; Caçador, I. Zostera noltii development probing using chlorophyll a transient analysis (JIP-test) under field conditions: Integrating physiological insights into a photochemical stress index. Ecol. Indic. 2017, 76, 219-229. [CrossRef]

38. Feijão, E.; de Carvalho, R.; Duarte, I.A.; Matos, A.R.; Cabrita, M.T.; Novais, S.C.; Lemos, M.F.L.; Caçador, I.; Marques, J.C.; Reis-Santos, P.; et al. Fluoxetine Arrests Growth of the Model Diatom Phaeodactylum tricornutum by Increasing Oxidative Stress and Altering Energetic and Lipid Metabolism. Front. Microbiol. 2020, 11, 1803. [CrossRef]

39. Duarte, B.; Cabrita, M.T.; Vidal, T.; Pereira, J.L.; Pacheco, M.; Pereira, P.; Canário, J.; Gonçalves, F.J.M.; Matos, A.R.; Rosa, R.; et al. Phytoplankton community-level bio-optical assessment in a naturally mercury contaminated Antarctic ecosystem (Deception Island). Mar. Environ. Res. 2018, 140, 412-421. [CrossRef] [PubMed]

40. Clarke, K.R.; Gorley, R.N. PRIMER v6: User Manual/Tutorial. Prim. Plymouth UK 2006, 192.

41. Yang, R.; Wei, D.; Xie, J. Diatoms as cell factories for high-value products: Chrysolaminarin, eicosapentaenoic acid, and fucoxanthin. Crit. Rev. Biotechnol. 2020, 40, 993-1009. [CrossRef]

42. Sirisuk, P.; Ra, C.-H.H.; Jeong, G.-T.T.; Kim, S.-K.K. Effects of wavelength mixing ratio and photoperiod on microalgal biomass and lipid production in a two-phase culture system using LED illumination. Bioresour. Technol. 2018, 253, 175-181. [CrossRef] [PubMed]

43. Goessling, J.W.; Cartaxana, P.; Kühl, M. Photo-protection in the centric diatom Coscinodiscus granii is not controlled by chloroplast high-light avoidance movement. Front. Mar. Sci. 2016, 2. [CrossRef]

44. Jeong, H.; Lee, J.; Cha, M. Energy efficient growth control of microalgae using photobiological methods. Renew. Energy 2013, 54, 161-165. [CrossRef]

45. Su, Y. The effect of different light regimes on pigments in Coscinodiscus granii. Photosynth. Res. 2019, 140, 301-310. [CrossRef]

46. Chandrasekaran, R.; Barra, L.; Carillo, S.; Caruso, T.; Corsaro, M.M.; dal Piaz, F.; Graziani, G.; Corato, F.; Pepe, D.; Manfredonia, A.; et al. Light modulation of biomass and macromolecular composition of the diatom Skeletonema marinoi. J. Biotechnol. 2014, 192, 114-122. [CrossRef]

47. Fábregas, J.; Maseda, A.; Domínguez, A.; Ferreira, M.; Otero, A. Changes in the cell composition of the marine microalga, Nannochloropsis gaditana, during a light:dark cycle. Biotechnol. Lett. 2002, 24, 1699-1703. [CrossRef]

48. Solovchenko, A.E. Physiological role of neutral lipid accumulation in eukaryotic microalgae under stresses. Russ. J. Plant Physiol. 2012, 59, 167-176. [CrossRef]

49. Ramos, M.J.; Fernández, C.M.; Casas, A.; Rodríguez, L.; Pérez, Á. Influence of fatty acid composition of raw materials on biodiesel properties. Bioresour. Technol. 2009, 100, 261-268. [CrossRef] [PubMed]

50. Calder, P.C. Functional Roles of Fatty Acids and Their Effects on Human Health. J. Parenter. Enter. Nutr. 2015, 39, 18S-32S. [CrossRef] [PubMed] 
51. Calder, P.C. Very long-chain n -3 fatty acids and human health: Fact, fiction and the future. Proc. Nutr. Soc. 2018, 77, 52-72. [CrossRef]

52. Mühlroth, A.; Li, K.; Røkke, G.; Winge, P.; Olsen, Y.; Hohmann-Marriott, M.; Vadstein, O.; Bones, A. Pathways of Lipid Metabolism in Marine Algae, Co-Expression Network, Bottlenecks and Candidate Genes for Enhanced Production of EPA and DHA in Species of Chromista. Mar. Drugs 2013, 11, 4662-4697. [CrossRef]

53. Dolch, L.-J.; Maréchal, E. Inventory of Fatty Acid Desaturases in the Pennate Diatom Phaeodactylum tricornutum. Mar. Drugs 2015, 13, 1317-1339. [CrossRef] [PubMed]

54. Matos, A.R.; Pham-Thi, A.-T. Lipid deacylating enzymes in plants: Old activities, new genes. Plant Physiol. Biochem. 2009, 47, 491-503. [CrossRef]

55. Feijão, E.; Franzitta, M.; Cabrita, M.T.; Caçador, I.; Duarte, B.; Gameiro, C.; Matos, A.R. Marine heat waves alter gene expression of key enzymes of membrane and storage lipids metabolism in Phaeodactylum tricornutum. Plant Physiol. Biochem. 2020, 156, 357-368. [CrossRef]

56. Walker, C.G.; Jebb, S.A.; Calder, P.C. Stearidonic acid as a supplemental source of $\omega-3$ polyunsaturated fatty acids to enhance status for improved human health. Nutrition 2013, 29, 363-369. [CrossRef] [PubMed]

57. Koller, M.; Muhr, A.; Braunegg, G. Microalgae as versatile cellular factories for valued products. Algal Res. 2014, 6, 52-63. [CrossRef]

58. McClure, D.D.; Luiz, A.; Gerber, B.; Barton, G.W.; Kavanagh, J.M. An investigation into the effect of culture conditions on fucoxanthin production using the marine microalgae Phaeodactylum tricornutum. Algal Res. 2018, 29, 41-48. [CrossRef]

59. Helmersson, J.; Ärnlv, J.; Larsson, A.; Basu, S. Low dietary intake of $\beta$-carotene, $\alpha$-tocopherol and ascorbic acid is associated with increased inflammatory and oxidative stress status in a Swedish cohort. Br. J. Nutr. 2009, 101, 1775-1782. [CrossRef]

60. Miyashita, K.; Beppu, F.; Hosokawa, M.; Liu, X.; Wang, S. Nutraceutical characteristics of the brown seaweed carotenoid fucoxanthin. Arch. Biochem. Biophys. 2020,686, 108364. [CrossRef]

61. Humphrey, G.F. The effect of the spectral composition of light on the growth, pigments, and photosynthetic rate of unicellular marine algae. J. Exp. Mar. Bio. Ecol. 1983, 66, 49-67. [CrossRef]

62. Mouget, J.-L.; Rosa, P.; Tremblin, G. Acclimation of Haslea ostrearia to light of different spectral qualities-confirmation of 'chromatic adaptation' in diatoms. J. Photochem. Photobiol. B Biol. 2004, 75. [CrossRef] [PubMed]

63. Depauw, F.A.; Rogato, A.; d'Alcala, M.R.; Falciatore, A. Exploring the molecular basis of responses to light in marine diatoms. J. Exp. Bot. 2012, 63, 1575-1591. [CrossRef] [PubMed]

64. Brunet, C.; Chandrasekaran, R.; Barra, L.; Giovagnetti, V.; Corato, F.; Ruban, A.V. Spectral Radiation Dependent Photoprotective Mechanism in the Diatom Pseudo-nitzschia multistriata. PLoS ONE 2014, 9, e87015. [CrossRef] [PubMed] 